\title{
Sistem Informasi Pengolahan Data Bantuan Beasiswa Siswa Miskin (BSM) Pada Kantor Wilayah Kementerian Agama Provinsi Maluku Utara
}

\author{
Sartika Muhammad Hadi ${ }^{1}$, Abjan Samad ${ }^{2}$ \\ Program Studi Manajemen Informatika ${ }^{1}$, Program Studi Teknik Komputer ${ }^{2}$ \\ Akademi Ilmu Komputer (AIKOM) Ternate \\ sartika_hadi01@gmail.com
}

\begin{abstract}
Abstrak
Pengolahan Data Bantuan Beasiswa Siswa Miskin (BSM) di Kantor Wilayah Kementerian Agama Provinsi Maluku Utara saat ini belum terkomputerisasi terkesan lambat, dalam pencarian Data Bantuan Beasiswa Siswa Miskin (BSM) memerlukan waktu yang lama sehingga dianggap kurang efisien, Tujuan penelitian ini adalah Membuat Sistem Informasi Pengolahan Data Bantuan Beasiswa Siswa Miskin untuk menghasilkan data yang lebih cepat dan akurat, Teknik Pengumpulan Data adalah Observasi, Interview dan Kepustakaan, Model rancangan yang digunakan adalah flowchart, DFD, ERD dan Kamus Data, Aplikasi yang digunakan untuk mengelola data bantuan beasiswa adalah Microsoft Visual Basic 6, Dengan Adanya Sistem Informasi Pengolahan Data Beasiswa Siswa Miskin (BSM) diharapkan dapat membantu Pihak Admin Kantor Wilayah Kementerian Agama Provinsi Maluku utara dalam mengolah data administrasi bantuan siswa miskin sehingga lebih efektif dan efisien
\end{abstract}

\section{Kata kunci: Sistem Informasi, Pengolahan Data Bantuan, Siswa Miskin}

\begin{abstract}
Data processing Help Poor Students Scholarship (BSM) in the Regional Office of the Ministry of religion of the North Maluku province is currently not yet computerized impressed slow, in the search for a Scholarship Assistance Data poor students (BSM) takes a long time so it is considered less efficient. The purpose of this research is to develop information systems Data processing Help Poor Students Scholarships to generate more data quickly and accurately, Data collection techniques are observation, Interview and Librarianship, The model used is the draft of the flowchart, DFD, ERD and Data Dictionary, Application used to manage data help scholarship is Microsoft Visual Basic 6, With the information systems Data processing Scholarships poor students (BSM) is expected to help the Admin Regional Office of the Ministry of religion of North Maluku province in the process data administration help poor students so that more effective and efficient
\end{abstract}

Keywords: Information System, Data Processing Help, Poor Students

\section{PENDAHULUAN}

Perkembangan teknologi saat ini mengalami kemajuan yang sangat pesat, ditandai bertambah canggih dan kompleksnya penggunaan teknologi pada kehidupan sehari-hari, seiring dengan hal tersebut manusia sebagai pemakai teknologi terus menerus memperbaiki dan memperbahurui aktifitas manusia itu sendiri, agar setiap tindakan maupun kegiatan dapat berjalan dengan efektif dan efisien. Perkembangan ilmu teknologi tersebut merambah pada Kementerian Agama, termasuk salah satunya dalam pengolahan data Bantuan Siswa Miskin (BSM).

Bantuan Siswa Miskin adalah bantuan yang diberikan kepada siswa dari keluarga 
kurang mampu untuk dapat melakukan kegiatan belajar di sekolah. Bantuan ini memberi peluang bagi siswa untuk mengikuti pendidikan di level yang lebih tinggi, selain itu tujuan utama adalah untuk mengurangi jumlah siswa putus sekolah akibat permasalahan biaya pendidikan. Kebijakan BSM bertujuan agar siswa dari kalangan tidak mampu dapat terus melanjutkan pendidikan di sekolah. Program ini bersifat bantuan yang diberikan pada siswa yang ekonomi yang kurang mampu.

BSM dikelola oleh Kementerian Agama disebut sebagai Bantuan Beasiswa Siswa Miskin (disatukan pengelolaannya antara bantuan dengan beasiswa). Sumber dana semua bantuan ini adalah dari APBN, alokasinya tertuang dalam DIPA di lingkup Kementerian Agama.

Kementerian Agama melalui APBN menetapkan program "Bantuan Beasiswa Siswa Miskin" yang diberikan kepada sebagian siswa miskin di tingkat Madrasah Ibtidaiyah (MI), Madrasah Tsanawiyah (MTs) dan Madrasah Aliyah (MA) walaupun jumlah siswa yang mendapatkan bantuan ini masih sangat terbatas.

Program "Bantuan Beasiswa Siswa Miskin" ini dananya berasal dari APBN yang diserahkan kepada Kantor wilayah masing-masing sebagai wujud tanggung jawab Pemerintah dalam rangka meningkatkan akses pendidikan yang lebih luas, sehingga terjangkau oleh masyarakat ekonomi lemah untuk semua siswa madrasah negeri maupun swasta.

Dengan program Bantuan Beasiswa Siswa Miskin ini diharapkan dapat membantu sebagian siswa yang berasal dari keluarga kurang mampu/miskin di lingkungan madrasah dalam membiayai sebagian kebutuhan pendidikannya, sehingga dapat menyelesaikan pendidikannya dan bahkan dapat melanjutkan pendidikan ke jenjang berikutnya.

Begitupun pada Kantor Wilayah Kementerian Agama Provinsi Maluku Utara khususnya pada bidang pendidikan, Pengolahan Data Bantuan Beasiswa Siswa Miskin (BSM) belum terkomputerisasi dalam mengerjakan hal-hal khususnya dalam pengolahan data BSM terkesan lambat dan tidak efisien dalam pencarian data BSM sehingga memerlukan waktu yang lama dalam pencarian data BSM.

Dengan menggunakan komputer, waktu penggerjaan dapat dihemat dan penyimpanan data dapat lebih aman di bandingkan dengan penyimpanan data dalam bentuk kertas di lemari arsip serta dapat mengurangi faktor manusia ( Human Error), oleh karena itu dirasakan perlu penggunaan komputer sebagai alat bantu untuk pengolahan data BSM sesuai kebutuhan instansi terkait, di butuhkan sebuah perangkat aplikasi yang dapat menunjang pengadministrasian data khususnya data BSM.

Oleh karena itu, dalam penulisan Tugas Akhir ini penulis mengusulkan pengembangan sistem dengan judul Sistem Informasi Pengolahan Data BSM pada Kantor Wilayah Kementerian Agama Provinsi Maluku Utara dengan menggunakan bahasa pemograman Visual Basic 6.0.

\section{Rumusan Masalah}

Bagaimana merancang suatu sistem informasi untuk mempermudah dalam pengumpulan dan penyimpanan data agar dalam pencarian data/informasi mengenai BSM di Kantor wilayah Kementerian Agama Provinsi Maluku Utara tidak lagi mengalami kesulitan. 


\section{Tujuan Penelitian}

Tujuan penelitian ini adalah Membuat Sistem Informasi Pengolahan Data Bantuan Beasiswa Siswa Miskin untuk menghasilkan data yang lebih cepat, tepat, akurat dan bermanfaat bagi instansi terkait.

\section{Manfaat Penelitian}

Untuk dapat membantu mengolah data administrasi bantuan siswa miskin yang dibutuhkan sehingga akan lebih efektif dan efisien

\section{Tinjauan Pustaka}

Septiawan dan Devis Raizal pada peniltian Sistem Informasi Beasiswa Pada Universitas Muhammadiyah Surakarta Menggunakan Php Dan Mysql Tahun 2013, mengatakan Lembaga pendidikan merupakan salah satu unsur yang mempunyai peranan penting dalam meningkatkan mutu sumber daya manusia yang baik dan berkualitas, hal ini perlu ditunjang dengan fasilitas - fasilitas yang dapat memenuhi kebutuhan akan pendidikan. Salah satunya program pemberian beasiswa bagi mahasiswa sebagai proses memenuhi kebutuhan akan pendidikan. Beasiswa itu sendiri adalah bantuan dan dukungan pendidikan yang diberikan kepada mahasiwa yang mengalami kesulitan ekonomi dan memilki prestasi yang baik. Penelitian ini bertujuan untuk menjelaskan dan mendiskripsikan sistem informasi beasiswa di Univesitas Muhammadiyah Surakarta, dengan membangun sistem informasi beasiswa. Laporan ini berisi dokumentasi serta pelaporan proses pengembangan dan perancangan sistem informasi beasiswa UMS yang dilakukan menggunakan metodologi SDLC. Proses dari metodologi yang tergabung dalam laporan ini adalah proses analisis sistem, perancangan sistem, implementasi dan pengujian sistem. Sistem informasi beasiswa ini dapat digunakan dalam menunjang pengolahan data serta publikasi informasi beasiswa kepada mahasiswa Universitas Muhammadiyah Surakarta.

Dian Sulistyo dan Sri Winiarti dalam penilitian yang berjudul Pemanfataan Informasi Teknologi Dalam Penentuan Beasiswa Siswa Kurang Mampu Tahun 2015 mengatakan bahwa Pendidikan merupakan salah satu kewajiban setiap warga negara Indonesia. Untuk mendukung program Pemerintah yaitu wajib belajar hingga 12 tahun, Dalam proses pengolahan data dan seleksi beasiswa pihak penyeleksi dari DIKPORA menggunakan software Microsoft Office Excel, sering menemui kendala diantaranya kesalahan dalam menginput identitas siswa maupun data penilaian. Kesalahan-kesalahan dalam menginput yang sering terjadi diantaranya data yang ditulis dua kali (double), Dari penelitian yang dilakukan menghasilkan sebuah perangkat lunak sistem pendukung keputusan untuk menentukan penerima beasiswa kurang mampu dengan metode Promethee dengan kemampuan yang dapat memberikan informasi dan rekomendasi penerima beasiswa yang disertai dengan nilai hasil perangkingan. Hasil uji coba menunjukkan bahwa aplikasi ini layak dan dapat digunakan.

Ardiyanto, Bayu and Somantri, Maman and Satoto, Kodrat Iman dalam penelitian Perancangan Sistem Informasi Beasiswa Universitas Diponegoro Berbasis Web tahun 2011 menjelaskan bahwa Universitas Diponegoro merupakan salah satu universitas negeri yang cukup dikenal luas di masyarakat, tentunya banyak sekali pihak-pihak yang ingin menawarkan beasiswa pada Universitas Diponegoro 
guna membantu kelancaran studi mahasiswanya yang berprestasi namun kurang mampu keadaan ekonominya. Oleh sebab itu perlu dikembangkan sistem informasi beasiswa berbasis web yang diharapkan nantinya penyampaian beasiswa dapat lebih tepat guna dan tepat sasaran. Tugas akhir ini mencakup perancangan dan pengembangan sistem informasi Beasiswa Universitas Diponegoro yang berbasis web. Perancangan perangkat lunak dalam tugas akhir ini menggunakan Unified Modeling Language (UML) dan Model View Controller untuk perancangan komponen yang dipakai. Sistem dengan tampilan antarmuka pengguna diatur dan dikendalikan oleh suatu halaman web yang dirancang dengan menggunakan Joomla! sebagai framework-nya dan bahasa pemrograman PHP yang berjalan pada layanan Apache. Terakhir adalah implementasi dan pengujian sistem yang meliputi proses implementasi basisdata, pengujian blackbox dan pengujian whitebox. Hasil pengujian aplikasi yang dirancang bekerja dengan sesuai dengan mekanisme aplikasi beasiswa yang dibuat. Aplikasi ini memiliki 3 level pengguna yaitu Administrator, pengguna terdaftar, dan pengguna umum. Aplikasi ini dapat menangani dengan baik proses pengelolaan dan pendaftaran beasiswa Universitas Diponegoro yang didukung dengan hasil survey dari kinerja sistem informasi yang sudah dibuat.

\section{LANDASAN TEORI}

\section{Pengertian Sistem}

Menurut Romney dan Steinbart (2015:3) Sistem adalah rangkaian dari dua atau lebih komponen-komponen yang saling berhubungan, yang berinteraksi untuk mencapai suatu tujuan.Sebagian besar sistem terdiridari subsistem yang lebih kecil yan mendukung sistem yang lebih besar

\section{Pengertian Sistem Informasi}

Menurut Kadir (2014:9), Sistem informasi adalah "sebuah rangkaian prosedur formal dimana data dikelompokkan, diproses menjadi informasi, dan didistribusikan kepada pemakai

\section{Analisa Sistem}

Menurut Abdul Kadir (2014:345), analisa sistem adalah proses untuk menentukan hal-hal detail tentang yang akan dikerjakan oleh sistem yang diusulkan (dan bukan bagaimana caranya). Tahapan analisa sistem dilakukan untuk mengembangkan sistem yang sudah ada atau mengatasi masalahmasalah yang belum tertangani Perancangan Sistem

\section{BSM}

BSM adalah bantuan yang diberikan kepada siswa dari keluarga kurang mampu untuk dapat melakukan kegiatan belajar di sekolah. Bantuan ini memberi peluang bagi siswa untuk mengikuti pendidikan di level yang lebih tinggi, Selain itu tujuan utama adalah untuk mengurangi jumlah siswa putus sekolah akibat permasalahan biaya pendidikan.

Kebijakan BSM bertujuan agar siswa dari kalangan tidak mampu dapat terus melanjutkan pendidikan di sekolah. Program ini bersifat bantuan bukan beasiswa, karena jika beasiswa bukan berdasarkan kondisi ekonomi siswa, melainkan berdasarkan kondisi ekonomi siswa melainkan berdasarkan prestasi.

\section{Flow Chart}


Ladjamudin (2013 : 211) mengemukakan bahwa, flowchart adalah bagan - bagan yang mempunyai arus yang menggambarkan langkah _ langkah penyelesaian suatu masalah. Flowchart merupakan cara penyajian dari suatu algoritma.

\section{DFD}

Sukamto dan Shalahuddin (2014:288), "Data Flow Diagram atau dalam bahasa Indonesia menjadi Diagram Alir Data (DAD) adalah refresentasi grafik yang menggambarkan aliran informasi dan transformasi informasi yang diaplikasikan sebagai data yang mengatur dari masukan (input) dan keluaran (output). DFD tidak sesuai untuk memodelkan sistem yang menggunakan pemograman berorientasi objek."

\section{ERD}

Sukamto dan Shalahuddin (2014:50), ERD memiliki beberapa aliran notasi seperti notasi Chen (dikembangkan oleh Peter Chen). Barker (dikembangkan oleh Richard Barker, Ian Palmer, Harry Ellis), notasi Crow's Foot, dan beberapa notasi lain. Namun yang banyak digunakan adalah notasi dari Chen. Berikut adalah simbol-simbol yang digunakan pada ERD dengan notasi Chen

\section{Kamus Data}

Menurut Rosa dan Shalahudin (2013:73), Kamus Data adalah kumpulan daftar elemen data yang mengalir pada sistem perangkat lunak sehingga masukan (input) dan keluaran (output) dapat dipahami secara umum (memiliki standar cara penulisan). Kamus data dalam implementasi program dapat menjadi parameter masukan atau keluaran dari sebuah fungsi atau prosedur

\section{Microsoft Visual Basic}

Menurut Stefano

(2014:2)

mengemukakan bahwa "visual basic merupakan sebuah bahasa pemrograman yang menawarkan Intergrated Development Environment (IDE) visual untuk membuat program perangkat lunak berbasis operasi Microsoft Windows menggunakan model pemrograman (COM)"

\section{METODE PENELITIAN}

Untuk mendapatkan data yang dibutuhkan dalam rangka penyusunan penelitian ini, maka Penulis mengumpulkan data melalui beberapa teknik pengumpulan data:

a. Observasi

Adalah teknik yang dilakukan dengan cara mengadakan pengamatan secara langsung mengenai sistem yang berjalan saat ini.

b. Interview

Adalah teknik wawancara untuk mendapatkan data yang relevan dengan pihak-pihak yang berwewenang berhubungan dengan penelitian.

c. Penelitian Pustaka (library research)

Merupakan teori-teori yang diambil dari berbagai referensi yang berhubungan dengan judul laporan Tugas Akhir.

\section{Kerangka Berpikir}

Kerangka berpikir yang baik akan menjelaskan secara teoritis hubungan antara variabel yang akan diteliti. Menurut Uma Sekaran (dalam Sugiyono, 2017:60), mengemukakan bahwa kerangaka berfikir merupakan model konseptual tentang bagaimana teori berhubungan dengan berbagai faktor yang telah didefinisikan 
sebagai

masalah yang penting

Mengamati sistem yang digunakan pada

Kantor Wilayah Kementerian Agama

Provinsi Maluku Utara

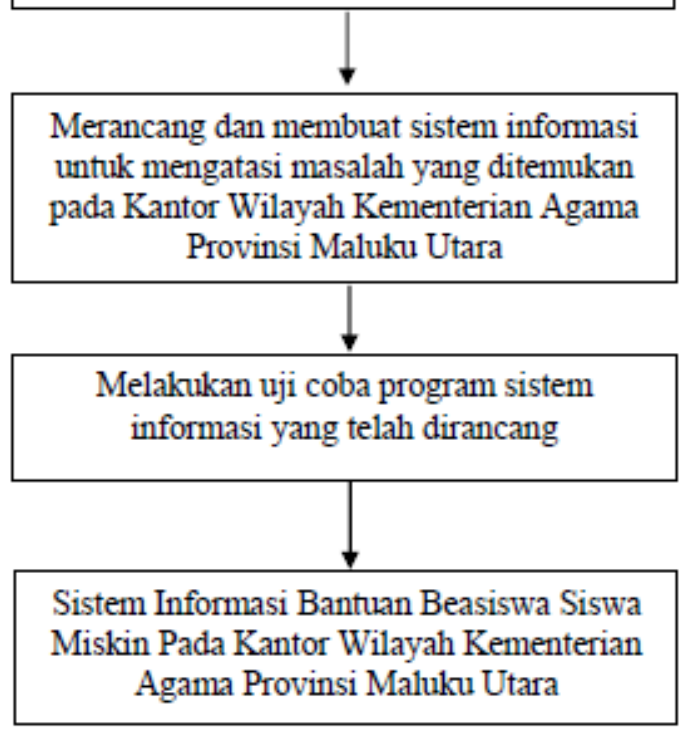

Gambar 1. Kerangka Berpikir

\section{Perangkat yang dibutuhkan Perangkat Keras}

a. RAM minimal $512 \mathrm{Mb}$

b. Processor Intel Pentium IV $2.0 \mathrm{GHz}$

c. Hardisk $80 \mathrm{~Gb}$

d. Monitor 15',

\section{Perangkat Lunak}

Perangkat Lunak yang digunakan pada penelitian ini yaitu Sistem Operasi Windows XP Profesional, Software Microsoft Visual Basic 6.0, Crystal Report dan Microsoft Acess 2007. Microsoft Visio 2007, Microsoft Word

\section{ANALISIS DAN PERANCANGAN}

Berdasarkan penelitian yang dilakukan pada Kantor Wilayah Kementerian Agama Provinsi Maluku Utara, dimana dalam melakukan proses pengolahan data Beasiswa Siswa Miskin masih menggunakan dengan cara sederhana / manual. Yang kami maksudkan secara manual yaitu hanya menggunakan program aplikasi Microsoft Office yaitu Word dan Excel, yang mana dalam melakukan pengolahan data BSM kurang efektif dan efisien.

Sehingga pada Kantor Wilayah Kementerian Agama Provinsi Maluku Utara, perlu dirancang lagi suatu sistem yang lebih baik dari sebelumnya. Sehingga untuk mecapai tingkat efektifitasnya baik itu dari segi waktu, biaya, dan tenaga yang menuju pada optimalisasi kerja dapat ditingkatkan

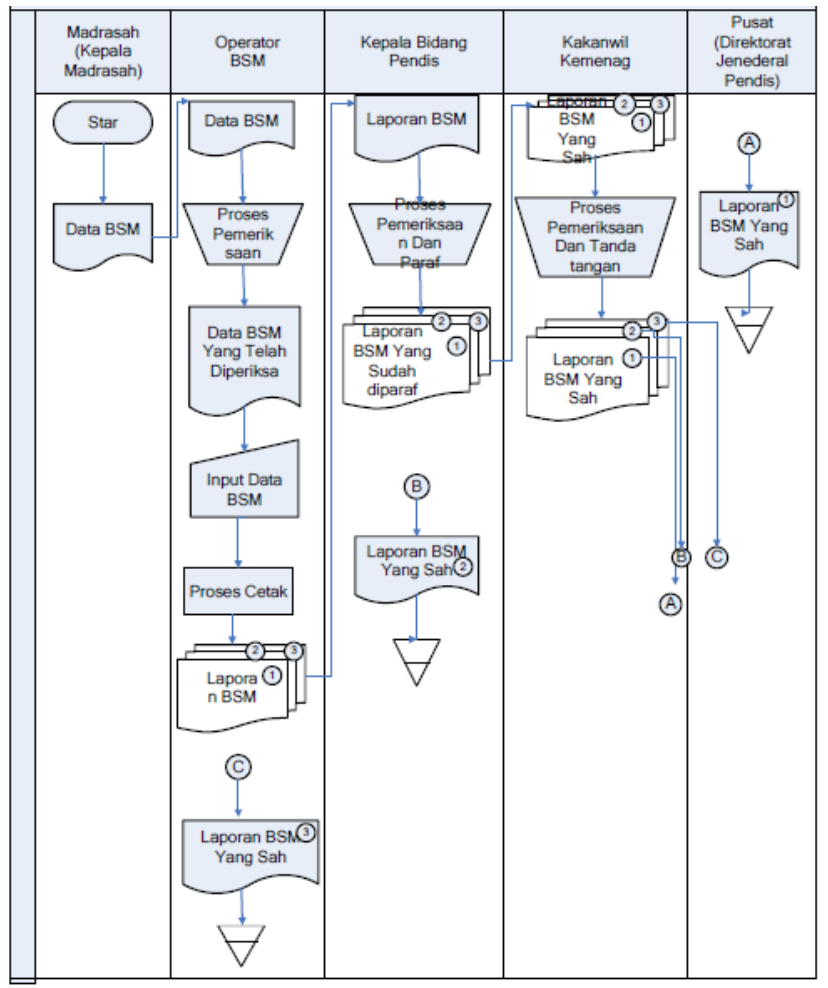

Gambar 2. Analisis Sistem berjalan

Sesuai dengan hal tersebut di atas, maka dalam pengolahan data Beasiswa Siswa Miskin pada Kantor Wilayah Kementerian Agama Provinsi Maluku Utara. penulis memberikan suatu pemecahan masalah dengan perancangan sistem pengolahan data secara otomatis yang menangani masalah pengolahan data Beasiswa Siswa Miskin Kantor Wilayah Kementerian Agama Provinsi Maluku Utara, sistem ini dipakai untuk mempermudah dalam mengolah data 
dalam penyusunan laporan, khususnya data penerima Beasiswa Siswa Miskin, dimana data tersebut disimpan dalam bentuk database, yang nantinya diproses secara akurat, dan dapat mempermudah suatu penghasilan informasi yang lebih baik. Analisis Sistem dapat di lihat pada gambar sebagai berikut:

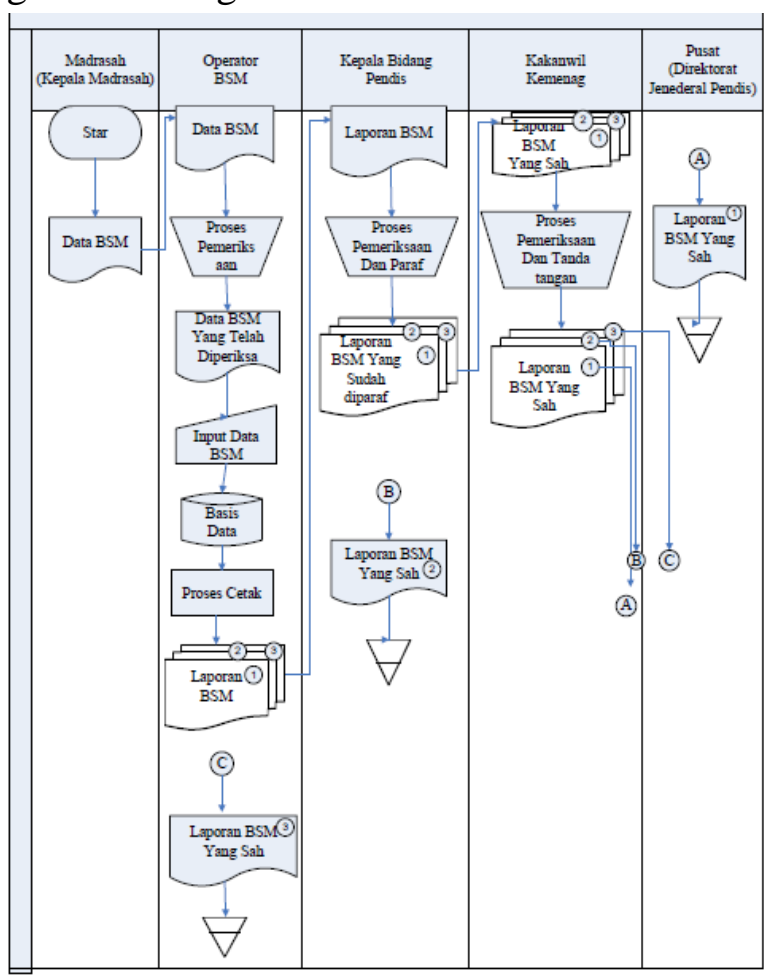

Gambar 3. Analisis Sistem yang diusulkan

\section{Diagram Konteks}

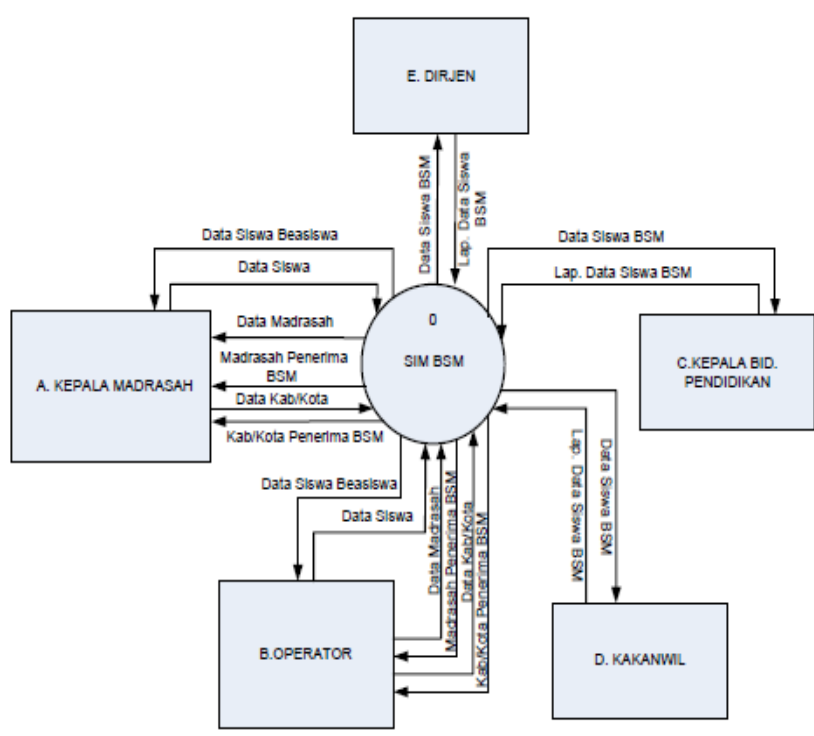

\section{Diagram Overview}

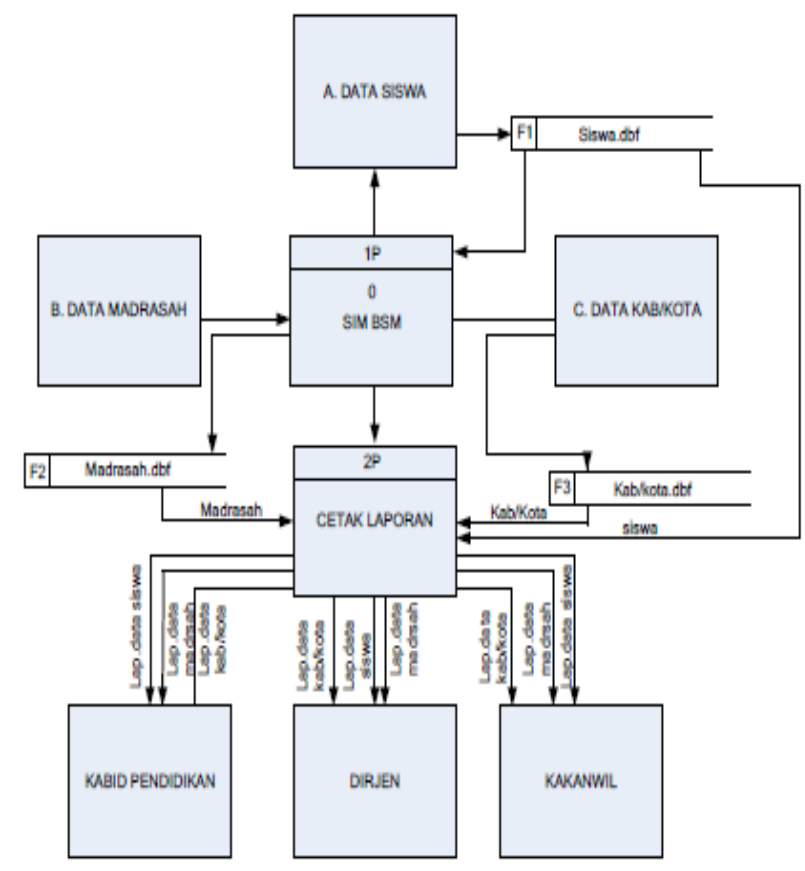

Gambar 5. Diagram Overview

\section{Kamus Data}

Tabel 1. Data Siswa

\begin{tabular}{|c|c|c|c|c|}
\hline Nama Field & Type & Widdh & Index & Keterangan \\
\hline NIS & Test & 12 & Primary key & Nouror Induls Siswa \\
\hline Nm_siswa & Test & 35 & & Nama Sisma \\
\hline Juis_Iamin & Test & 10 & & Jenis Kelamin \\
\hline Kelas & Test & 4 & & Relas \\
\hline Tmpt_Lhr & Test & 20 & & Tenæat Lahir \\
\hline Tgl_Lhr & Date & 8 & & Tanggal Lahir \\
\hline Alamat & Test & 15 & & Alamat \\
\hline Nin_Ayh & Test & 25 & & Nama Ayah \\
\hline Nin_Iba & Test & 15 & & Nama Tou \\
\hline Nin_Wab & Tesst & 25 & & Nama Wali \\
\hline Jnl_Saudr & Test & 9 & & Jumanh Saudara \\
\hline Anlk_Ke & Test & 5 & & Anak Ke \\
\hline $\begin{array}{l}\text { Pughstn } \\
\text { ortu_Perbln }\end{array}$ & Text & 10 & & $\begin{array}{l}\text { Penghasilan Orangrua } \\
\text { Perbulan }\end{array}$ \\
\hline Kd_Mad & Test & 12 & & Kode Madisah \\
\hline Nm_Mad & Text & 25 & & Nama Macrasah \\
\hline Kd_Kbptm & Test & 3 & & Kode Kabupaten \\
\hline Nm_Kbptn & Test & 25 & & Nama Ksibuparen \\
\hline Thn_trma & Test & 5 & & Talnu Terima \\
\hline
\end{tabular}

Gambar 6. Diagram Konteks 
Tabel 2. Data Madrasah

\begin{tabular}{|c|c|c|c|c|}
\hline Nama Field & Type & Width & Inder & Keterangan \\
\hline Fd Mand & Test & 15 & Primary key & Kode Madnasah \\
\hline Nin _ Mad & Test & 30 & & Nam Madrasah \\
\hline Alamat & Test & 25 & & Alament \\
\hline Kd_Pos & Test & 5 & & Kode Pos \\
\hline $\mathrm{NM}$ & Text & 12 & & Nomor Inctuk Madrasah \\
\hline Tp_KplMand & Text & 12 & & Telepon Kepala Madrasah \\
\hline Desa & Text & 8 & & Desa \\
\hline Kex & Test & 15 & & Kecamatan \\
\hline Kd_lab & Test & 3 & & Kode Kabupaten \\
\hline Nin I lab & Test & 15 & & Nam Kabupaten \\
\hline Nin Rels Mand & Text & 3 & & Nam Rekening Madrasah \\
\hline No_Rek Mad & Test & 12 & & Nomor Relkening Madrasah \\
\hline
\end{tabular}

Tabel 3. Data Kabupaten/Kota

\begin{tabular}{|c|c|c|c|c|}
\hline Nama Feld & Type & Whith & Index & Ketengngm \\
\hline $\mathrm{Kd}$ _lab & Text & 3 & Primary bey & Kade Kabuquten \\
\hline Nu__abo & Tesst & 15 & & Nam Kafoupaten \\
\hline
\end{tabular}

\section{Relasi Tabel}

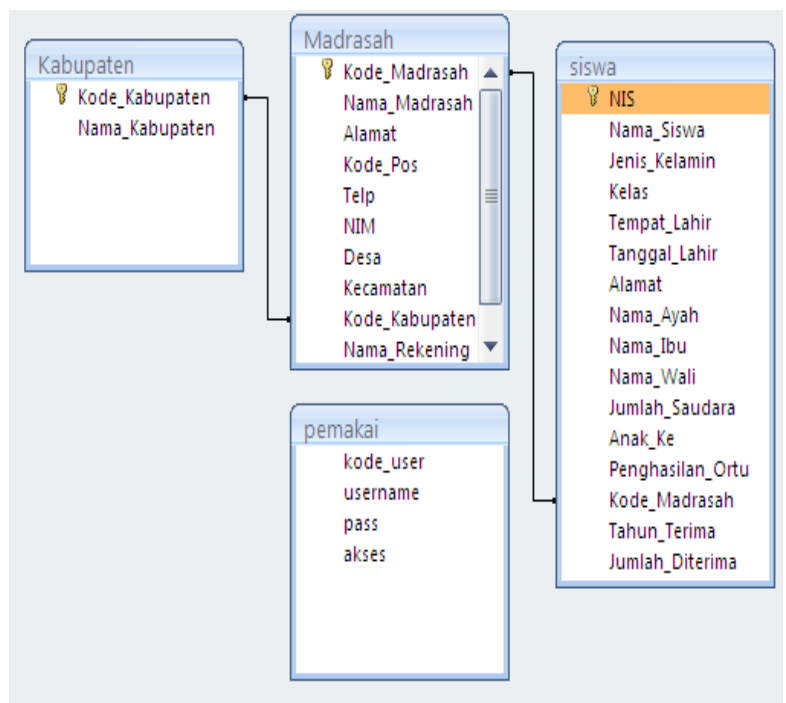

Gambar 7. Relasi Tabel

\section{Rancangan Struktur Menu}

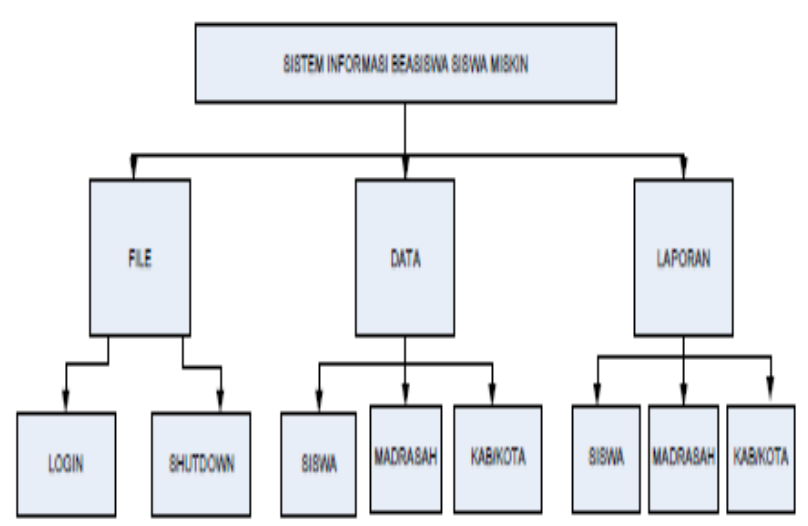

Gambar 6. Struktur menu

\section{Layout Menu}

Form Menu Utama

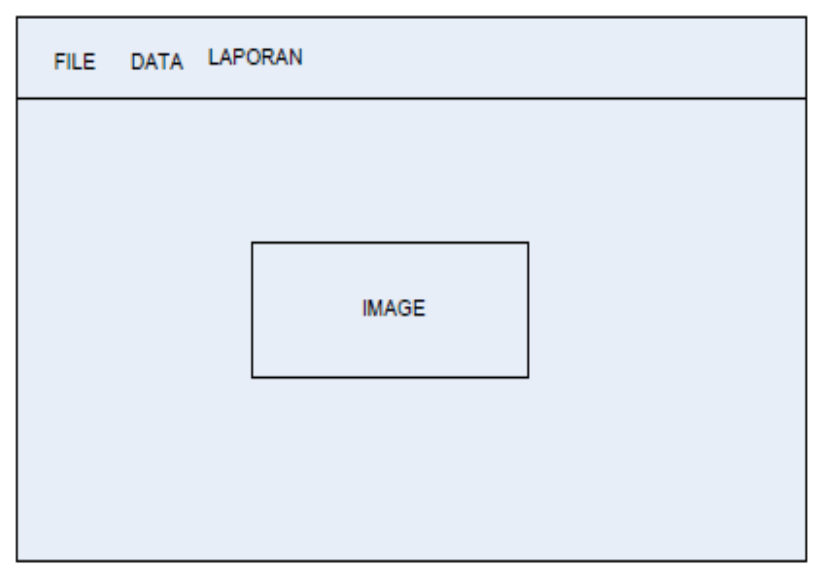

Gambar 8. Menu utama

\section{Form Data siswa}

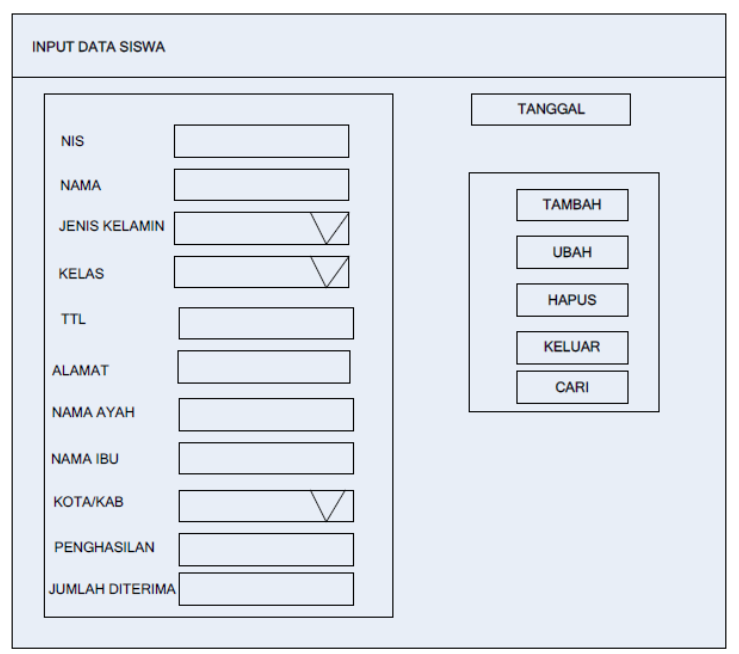

Gambar 9. Data Siswa 


\section{Form data Madrasah}

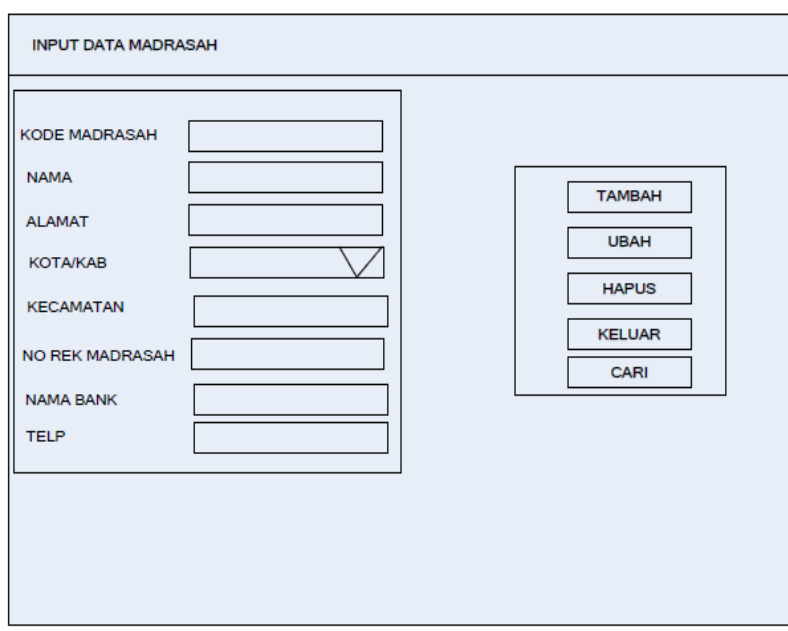

Gambar 10. Data Madrasah

\section{Form Data Kota/Kabupaten}

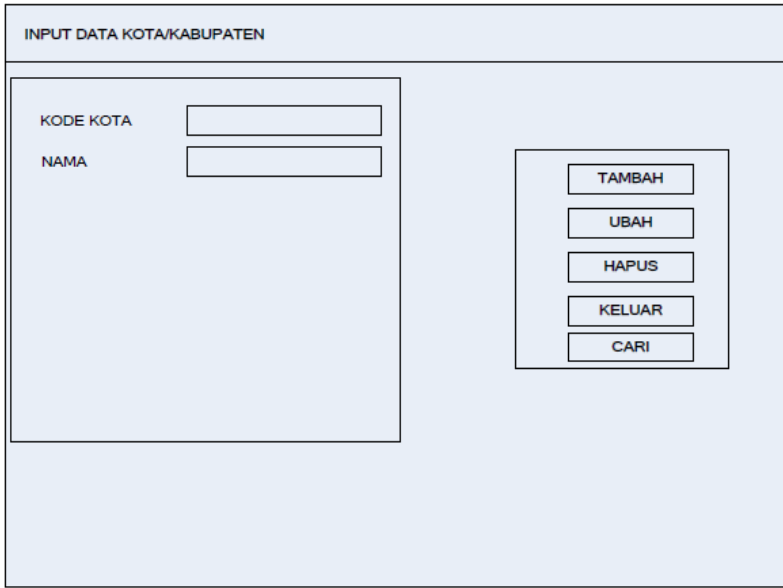

Gambar 11. Data Madrasah

\section{IMPLEMENTASI DAN PEMBAHASAN \\ Menu Utama}

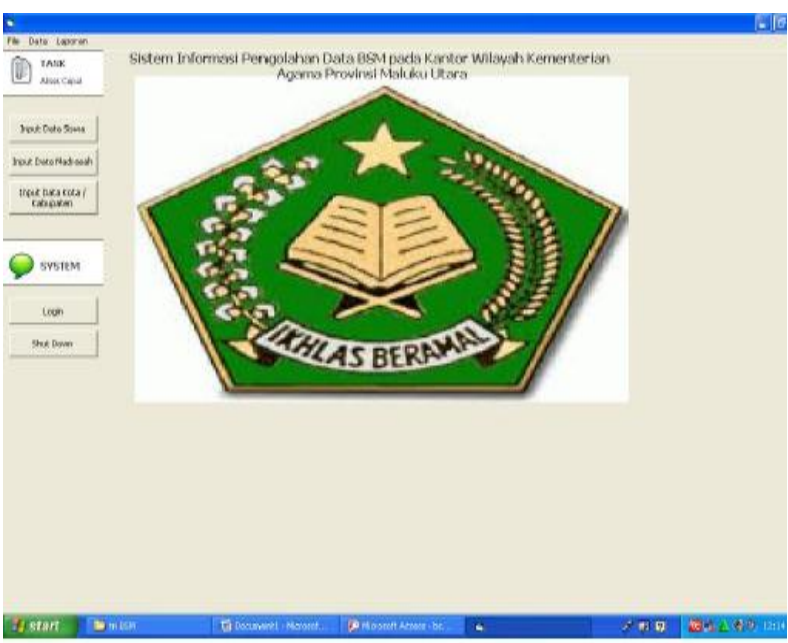

Gambar 12. Data Madrasah

\section{Menu Data Siswa}

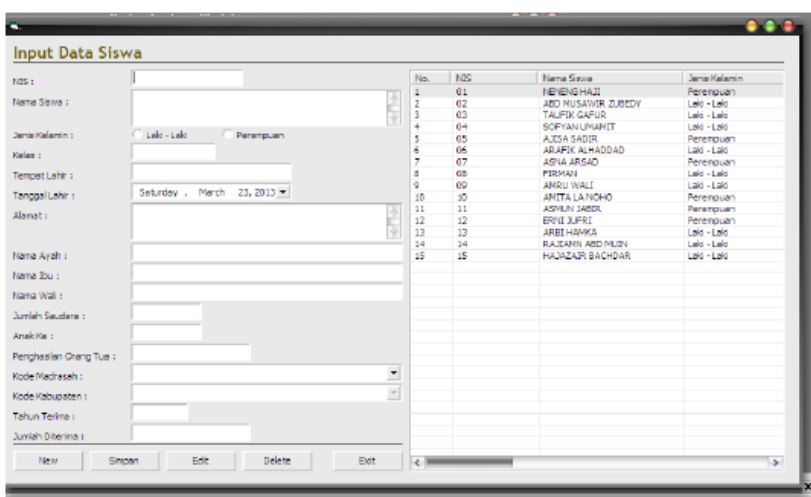

Gambar 13. Data Siswa

\section{Menu Data Madrasah}

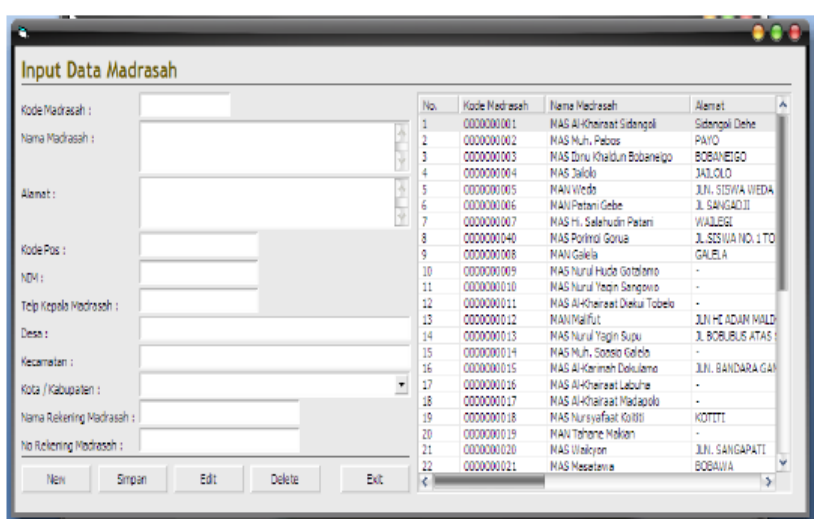

Gambar 14. Data Madrasah

\section{Menu data Kabupaten/Kota}

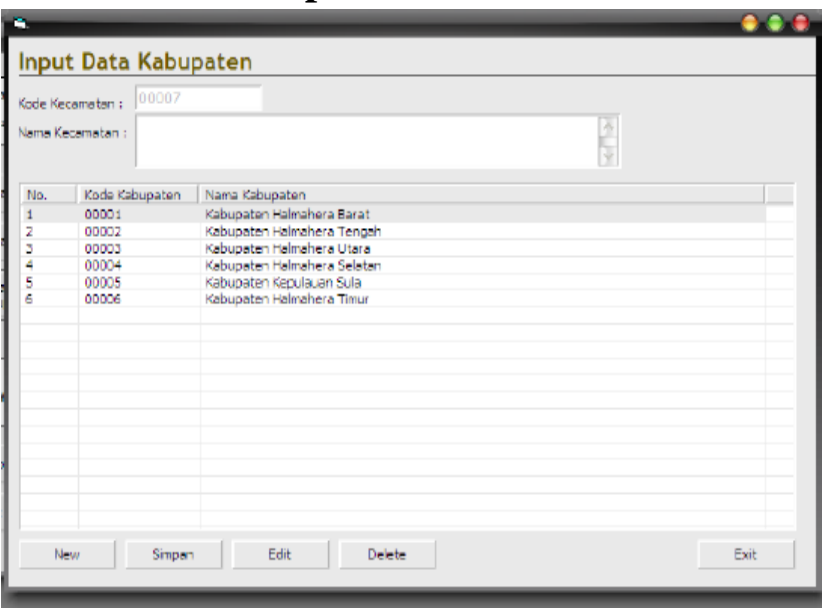

Gambar 15. Data Kabupaten

\section{Menu Data Laporan}

Menu data laporan merupakan menu untuk melihat hasil rekapan laporan data beasiswa yang dikelola sebelumnya pada sistem tersebut 


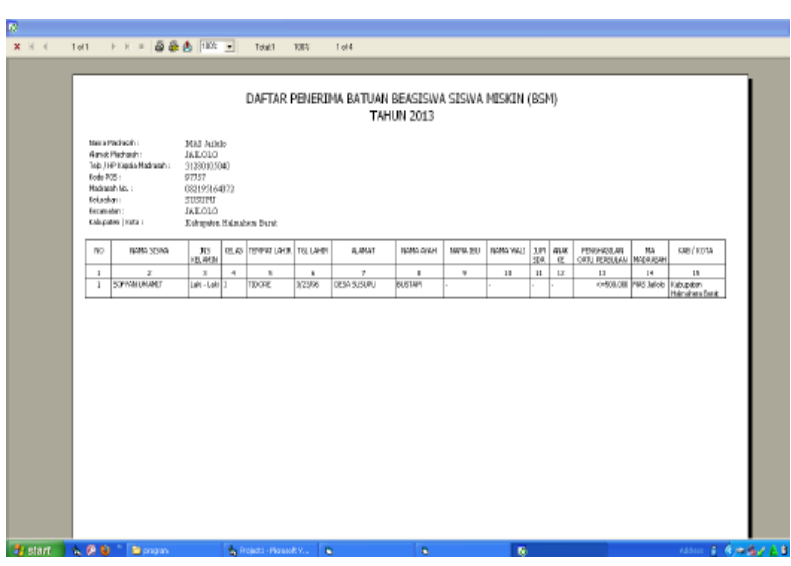

Gambar 16. Data Laporan

\section{KESIMPULAN}

1. Program aplikasi ini dapat membantu Kantor Wilayah Kementrian Agama Provinsi Maluku Utara dalam proses pengolahan data BSM.

2. Dengan adanya pengolahan informasi ini dengan menggunakan Pemograman visual Basic 6.0, diharapkan admin dapat mengetahui dengan mudah tentang Sistem Informasi Pengolahan Data Bantuan Beasiswa Siswa Miskin pada Kementerian Wilayah Provinsi Maluku Utara.

\section{Saran}

1. Pada Kantor Wilayah Kementrian Agama Provinsi Maluku Utara, agar dilakukan sosialisasi terhadap program ini dan perlu mengoptimalkan fungsi keterlaksanaan dengan melalui upaya pembentukan Sumber Daya Manusia (SDM) yang profesional agar dapat mengoptimalkan teknologi Informasi

2. Pengembangan berikutnya adalah sistem informasi ini dikelola dalam server online.

\section{DAFTAR PUSTAKA}

Alama, Agus. M, 2000, Manajemen Data Base dengan Microsoft Visual Basic 6.0, PT. Alex Media Komputindo, Jakarta
Departemen Pendidikan Nasional Dan Departemen Agama (2006), Petunjuk Pelaksanaan Bantuan Beasiswa Siswa Miskin, Jakarta Depdiknas, diakses tanggal 11 November 2012

Kadir, Abdul, 2000, Konsep dan Tuntunan Praktis Basis Data, Yogyakarta, Penerbit Andi

Sukamto, R. A., dan Shalahudin, M. 2014, Rekayasa Perangkat Lunak Terstruktur Dan Berorientasi Objek. Bandung: Informatika Bandung

A. S., Rosa dan Shalahuddin, M. 2013. Rekayasa Perangkat Lunak Terstruktur Dan Berorientasi Objek. Informatika. Bandung

Stefano, 2014, Cara Mudah Membangun Sistem Informasi Menggunakan VB.Net dan Komponen DXPerlence, Andi Offset, Yogyakarta.

Al-Bahra Bin Ladjamudin. 2013. Analisis dan Desain Sistem Informasi. Graha Ilmu. Yogyakarta.

Marshall B. Romney dan Paul John Steinbart. 2014. Sistem Informasi Akuntansi:

Accounting Information Systems (Edisi 13), Prentice Hall.

Abdul Kadir. 2014. Pengenalan Sistem Informasi Edisi Revisi. Andi.Yogyakarta

Septiawan, Devis Raizal (2013). Sistem Informasi Beasiswa Pada Universitas Muhammadiyah Surakarta Menggunakan Php Dan Mysql. Skripsi, Electronic Theses and Dissertations Universitas Muhammadiyah Surakarta.

Dian Sulistyo, Sri Winiarti, Pemanfaatan Informasi Teknologi dalam Penentuan Beasiswa Kurang Mampu, Jurnal Informatika Vol 9 No 1 Tahun 2015, ISSN 1978-0524 (Print) 2528-6374 (online)

Sugiyono. (2017). Metode Penelitian Kuantitatif, Kualitatif, dan $R \& D$. Bandung: Alfabeta 